\title{
Los hombres reunidos en la plaza: la toma de decisiones colectivas en el mundo antiguo
}

\author{
Marina Picazo GuRINA \\ Universitat Pompeu Fabra, Barcelona \\ marina.picazo@upf.edu
}

Recibido: 22 de diciembre de 2011

Aceptado: 27 de agosto de 2012

\section{RESUMEN}

Este trabajo propone que la emergencia de las jerarquías basadas en la desigualdad social no implicó necesariamente la eliminación del concepto y práctica de la comunidad. Aunque el poder centralizado es una característica de los sistemas complejos, siguieron existiendo formas colectivas de toma de decisiones. Las manifestaciones más destacadas de estas prácticas colectivas fueron las asambleas, espacios que simbolizan el poder colectivo como forma de llegar a consensos para el bien común. Se sugiere en este artículo que las asambleas del mundo antiguo, al igual que las que han existido en épocas históricas posteriores, representaban el poder del pueblo a pesar de la manipulación y las limitaciones impuestas por las autoridades jerárquicas.

Palabras clave: Asamblea. Toma de decisiones. Comunidad. Jerarquía. Manipuladores ambiciosos.

\section{Men gathered in the assembly: collective decision-making in the ancient world}

\begin{abstract}
This paper suggests that the emergence of hierarchies based on social inequality, does not necessarily imply the elimination of concept and practice of community. Even although the centralized power is a characteristic of complex systems, this did not mean that collective forms of decision-making were absent. The primary manifestations of these collective practices were the assemblies, as space that symbolizes the communal based power as a means of arriving at consensus for the common good. It is argued here that assemblies in the ancient world as well as those in later historical context represent the power of the people in spite of the manipulation and restriction imposed by hierarchical authority.
\end{abstract}

Key words: Assembly. Decision-making. Community. Hierarchies. Aggrandizers.

Sumario: 1. Introducción. 2. El papel de las gentes comunes en las sociedades complejas. 3. Asambleas y decisiones colectivas. 4. Asambleas romanas 5. La rendición de cuentas y la asamblea ateniense. 6 . Conclusiones. 
De hecho, hoy la mayoría juzga, delibera, elige en las asambleas públicas, y todos sus decretos recaen sobre casos particulares. Cada uno de sus miembros, considerado aparte, es inferior, quizá, si se le compara con el individuo de que acabo de hablar; pero el estado se compone precisamente de esta mayoría, y una comida en que cada cual lleva su parte es siempre más completa que la que pudiera dar por sí solo uno de los convidados. Por esta razón, la multitud, en la mayor parte de los casos, juzga mejor que un individuo, cualquiera que él sea (Aristóteles, Política 1281b).

A third attribute of civil leadership is the gift of oratory, normally to be exercised on behalf of tribal harmony and the good old traditional ways (LowIE 1973, 288)

Over the urban regimes the communal past hung like a ghost (BRADY 1997, 249).

\section{Introducción}

En la descripción homérica del escudo de Aquiles se describen dos ciudades, en una de las cuales los hombres están reunidos y participan, como comunidad, en la toma de decisiones sobre un conflicto entre vecinos:

Se había producido un litigio: dos hombres se disputaban el dinero para pagar por otro hombre al que uno de ellos había matado; éste aseguraba haber pagado ya todo, y lo acreditaba ante el pueblo; el otro negaba haber recibido nada. Los dos apelaban a un testigo en busca de la prueba decisiva. El pueblo aclamaba a ambos, apoyando a uno o a otro, mientras los heraldos contenían a la multitud. Los ancianos, sentados en piedras lisas, en el sagrado corro, tenían en sus manos los cetros de los heraldos, de sonoras voces, y poniéndose en pie, uno tras otro, emitían sus dictámenes. ${ }^{1}$

Los miembros de la comunidad se han reunido en el espacio público por excelencia, la plaza, para ser testigos y dar opinión sobre el desacuerdo provocado por un homicidio, que será juzgado por los ancianos, mientras los demás participantes muestran sus opiniones, gritando a favor de uno $\mathrm{u}$ otro bando. Aparecen en esta descripción elementos relacionados con lo que conocemos sobre el funcionamiento de la asamblea en la polis griega. En el período clásico los ciudadanos participaban y, en alguna medida, controlaban la esfera pública través de la asamblea donde la multitud escuchaba a los oradores y mostraba sus opiniones en forma de aclamación o protesta. ${ }^{2}$ Los miembros de la comunidad participaban también en aspectos relacionados con la jurisdicción, como vemos en la escena del escudo de Aquiles, donde la multitud no juzga directamente el conflicto, pero sí a los ancianos que actúan como jueces $\mathrm{y}$ de los que esperan veredictos justos.

La poesía homérica, como es bien sabido, se centra en los príncipes heroicos que compiten entre sí para alcanzar honor y estatus por su comportamiento en el combate y por su capacidad de persuasión en la asamblea o el consejo. Sin embargo, en diversas formas, la épica homérica refleja también un contexto social más complejo donde

1 Ilíada 18, 497-508. Traducción de Emilio Crespo Güemes (2000).

2 SChWATZBERG 2010. 
la gente común, los soldados ante Troya, o los campesinos/ciudadanos en tiempos de paz, tienen un papel en los procesos de toma de decisiones. De hecho, en la épica homérica la ciudad se presenta como una comunidad de personas, que comparten un territorio, costumbres y leyes y que está dotada de instituciones para la toma de decisiones y de lugares de encuentro comunal. ${ }^{3}$ El escenario por excelencia de esa agencia de la gente común es el que se relaciona con los procesos colectivos de deliberación. Tanto en la Ilíada como en la Odisea encontramos menciones a asambleas y consejos, donde se proponen debates públicos para solucionar problemas que afectan a la colectividad, sea el ejército o los habitantes de la comunidad. Los oradores, cuyo derecho a hablar depende de su estatus, rango o grado de experiencia, ejercen la autoridad comunal que, en ocasiones, se visibiliza mediante el cetro de poder. Normalmente solo hablan los líderes de la comunidad o los jefes militares, y los restantes hombres expresan su opinión colectivamente, mostrando su aprobación o desaprobación. Sin embargo, el orador ha de respetar la opinión de los reunidos, porque si no lo hace y su propuesta fracasa, podrá ser censurado públicamente, como teme Héctor que le suceda antes de iniciar su combate con Aquiles. ${ }^{4}$ Los miembros de la asamblea han de "ser persuadidos" por la habilidad de los oradores, lo que aleja la amenaza de la subordinación u obediencia, términos relativamente negativos en el discurso moral griego. ${ }^{5}$ Las gentes reunidas son testigos, aprueban y legitiman (o no) las acciones y decisiones que se les proponen -y que, por tanto, pasan a ser comunales- y que afectan a temas diversos, desde la distribución del botín a la resolución de conflictos entre los príncipes.

Las asambleas homéricas no son más que uno de los muchos ejemplos que el mundo antiguo nos proporciona sobre el papel de la comunidad en la toma de decisiones, incluso en sociedades fuertemente jerarquizadas. Es lo que sucede con la sociedad romana que se ha presentado, con frecuencia, como el caso paradigmático de una sociedad en la que los valores de la élite aristocrática, construidos a partir de las costumbres ancestrales, mores maiorum, institucionalizaron las desigualdades sociales y económicas. El papel de las familias aristocráticas en la organización del sistema político parecía eliminar la posibilidad de alguna forma de participación popular en los procesos de toma de decisiones. Sin embargo, como señala el lema SPQR: Senatus Populusque Romanus, una de las bases ideológicas de la cultura política romana era la participación del Pueblo Romano en importantes aspectos del gobierno. Durante la República se mantuvieron en funcionamiento instituciones plebeyas, desde magistrados propios (los tribunos de la plebe) a una importante participación en los procesos de toma de decisiones en asambleas en las que se promulgaban leyes y se elegían los cargos políticos más importantes. Lo mismo se ha documentado en otras sociedades antiguas, consideradas tradicionalmente como ejemplos primarios de los procesos de centralización del poder en manos de élites o monarcas. Así, en las ciudades mesopotámicas, donde se tiene evidencia de la existencia de asambleas locales constituidas por miembros de la comunidad que ejercían funciones judiciales y podían, en ocasio-

3 RaAflaub 1997, 630.

4 Il. 22, 99-110.

5 GrIFFITH 1998, 25-6. 
nes, oponerse a las decisiones tomadas desde el palacio y la corte real. ${ }^{6}$ Sin embargo, esa evidencia reiterada no ha tenido mucha influencia en las narrativas históricas sobre la emergencia de los estados arcaicos, generalmente asociada a la iniciativa de grupos reducidos de individuos o familias poderosas.

La idea original de este trabajo procede, en primer lugar, de mi perplejidad ante la reiterada insistencia de la historiografía moderna en que la idea de la comunidad de miembros con iguales derechos tuvo que ser inventada en una sociedad jerarquizada y por parte de miembros de la clase dominante. ${ }^{7}$ El objetivo principal es proponer ${ }^{8}$ que la participación de las gentes comunes libres en los procesos de toma de decisiones se mantuvo como una característica de las formas políticas en las sociedades complejas. Es uno de los rasgos fundamentales del conjunto de actitudes y prácticas "democráticas" que existieron anteriormente a la democracia ateniense, en culturas muy alejadas entre sí en el tiempo y el espacio. De hecho, la propia existencia de la asamblea, como reunión deliberativa, responde a la importancia del sentimiento comunitario en las sociedades humanas, en estrecha conexión con la tendencia al igualitarismo entre quienes pertenecen a un grupo. ${ }^{9} \mathrm{Al}$ mismo tiempo, ese sentimiento comunal se presenta ligado al rechazo a aceptar el poder injusto de individuos o grupos competitivos con tendencia a dominar políticamente y acumular riquezas, los "reyes devoradores de dones" de Hesíodo. ${ }^{10}$ Ese rechazo fue una de las causas principales de los conflictos conocidos en diversas poleis a lo largo de los siglos VII y VI a.C., donde los campesinos no pertenecientes a la elite estaban dispuestos a oponerse, incluso por la fuerza, a las familias terratenientes que controlaban las instituciones políticas del mundo griego arcaico. Esa hostilidad se expresaba en los intentos repetidos de reprimir el comportamiento de los individuos ambiciosos en las asambleas en las que se daba a los participantes, los miembros libres de la comunidad, la ocasión de mostrar su opinión en la toma de decisiones colectiva.

\section{El papel de las gentes comunes en las sociedades complejas}

Durante largo tiempo, los estudios sobre las primeras civilizaciones han tratado de establecer una definición común de las primeras sociedades complejas a partir de la emergencia de una serie de características, como territorios extensos, dirigidos por elites o gobernantes unipersonales, control por esas mismas elites de las redes de producción y distribución de bienes, imposición de leyes y normas al resto de la comunidad. Esa imagen de los primeros estados se impuso a partir de la aparente lógica de la teoría de la evolución de las sociedades, que desde la simplicidad de las bandas prehistóricas de recolectores presuponía la existencia de un estadio final, cuando la

6 YofFee 2005, 61.

7 Es decir, Solón y Clístenes y la democracia ateniense.

8 Como han hecho anteriormente autores como Morris 1996 o RoBINSON 1997 para las comunidades griegas arcaicas.

9 Normalmente esa tendencia igualitaria se limita a los hombres adultos del grupo y, por tanto, presenta limitaciones ligadas al sexo y a la edad, además de las relacionadas con la condición de extranjero o siervo.

10 Hes., Op. 263-4. Sobre este tema, Picazo 2013. 
centralización del poder permitió la aparición de ciudades, los avances tecnológicos, la arquitectura y los monumentos, la invención de sistemas de comunicación sofisticados, y la conquista de territorios y poblaciones. ${ }^{11}$ De esa forma, los primeros estados se convertían en el punto final de una supuesta madurez de los sistemas sociales, tras una larga historia evolutiva. Su emergencia, con diversas consecuencias económicas, tecnológicas, políticas y sociales, se atribuía, en medida importante, a la iniciativa y capacidad de creación, ordenación y, por supuesto, mando, de las élites. El remate final de esa construcción sería el desarrollo de una ideología que permitía no solo justificar el dominio sino también su continuidad a través de las generaciones, debido a la inevitable tendencia a la creación de dinastías por parte de los ricos y poderosos. En las narrativas sobre los orígenes de las primeras civilizaciones, gradualmente desaparecen los demás miembros de la sociedad, excepto en su condición de participantes en las obras (conquistas, obtención de excedentes, construcción de monumentos) que eran consecuencia y, a la vez, imagen, del predominio de las clases dirigentes. Ese orden social se mantenía a través de rituales y ceremonias que, de nuevo, han sido consideradas como una forma de celebración de los miembros de la élite y que permitían transmitir la ideología de la 'naturalidad' de su diferencia respecto al resto de la sociedad.

Se trata, por tanto, de un discurso historiográfico que se fundamenta en la creencia ${ }^{12}$ de que el motor primario en el desarrollo de las sociedades complejas ha sido la emergencia de un liderazgo centralizador acompañando a la diferencia social. Además, esa premisa se refuerza por la idea de las elites creadoras de cultura, riqueza y orden social, es decir de aquellos rasgos que se convierten en definitorios de la propia idea de civilización. ${ }^{13}$ En esa perspectiva las formas en las que, incluso en una sociedad jerarquizada, se negocia la distribución del poder entre los diversos grupos sociales se han omitido de forma prácticamente sistemática, con lo que se ha dado poca importancia a aspectos como el de la participación popular en la toma de decisiones.

Otra consecuencia de la importancia de las narrativas basadas en la evolución social de lo simple a lo complejo, ha sido que las prácticas y relaciones creadas en las etapas anteriores a la aparición del Estado hayan sido consideradas de forma negativa, al carecer de los rasgos que definen a las sociedades complejas: magistraturas organizadas, organización política jerarquizada, propiedad desigual de los recursos. De esa forma, su posible continuidad en etapas posteriores y, sobre todo, su relación con el rol de los grupos subordinados en la negociación social en el seno de las sociedades complejas, se ha ignorado. Es cierto, sin embargo, que en los últimos años diversos autores han empezado a proponer que las gentes comunes siempre han participado de forma activa en las interacciones sociales, fuese a través de la cooperación con las élites, de la resistencia o incluso de la huida. ${ }^{14}$ Esa participación implicaba, en algunos casos, dotar a los rasgos propios de la civilización, como las construcciones

11 Yoffee 2005, 2.

12 Utilizo este término porque no se trata tanto de una reflexión basada en el resultado de una evidencia empírica sino en una premisa ideológica no reconocida como tal.

13 Yoffee 2000, 46.

14 Joyce - ArnAud - LeVine 2001. 
monumentales o las conquistas territoriales, de significado comunal y no considerarlos tan solo una consecuencia de las iniciativas de las élites. ${ }^{15}$ Es decir, se trata de reconocer que la centralización del poder se sostenía, en cierta forma, en la implicación de la gente común en las negociaciones sociales. Una prueba de esa afirmación reside en el hecho comprobado en diversos contextos históricos de que, aunque la elite lograse mantener de forma estable el poder y lo usara para apropiarse del trabajo colectivo a lo largo de generaciones, seguía manteniendo un reconocimiento, implícito o explícito-SPQR-de la participación popular de diversas formas, aunque solo fuese para no enfrentarse a formas abiertas de resistencia. Es decir, incluso en sociedades extremadamente jerarquizadas, se conservan rasgos más o menos vivos del pasado comunal, anterior a los procesos de centralización del poder y de emergencia de las elites sociales.

Es cierto, como ya hemos señalado, que en la narrativa tradicional sobre la formación de las sociedades complejas se ha tendido de forma excesiva a suponer que las instituciones de negociación social creadas por la gente común fueron sustituidas por las instituciones formales propias de los estados. Es probable que ello se deba a la suposición de considerar que esas instituciones "no formalizadas" eran propias de una etapa poco evolucionada de las sociedades humanas. En cierta medida, las prácticas sociales de la 'gente común' han compartido, en el discurso historiográfico, la invisibilidad de las mujeres y por las mismas razones. Sin embargo, se ha demostrado en diversos casos que las prácticas populares y las instituciones estatales pueden existir conjuntamente, como apunta Forsdyke ${ }^{16}$ en relación a la "justicia popular" que en las poleis griegas era un mecanismo de mantenimiento del orden social que coexistía con las estructuras judiciales formales. Además, con frecuencia la justicia popular asumía la forma de decisión colectiva dirigida contra aquellos miembros del grupo, mayoritariamente pertenecientes a la elite, que habían quebrantado las normas de la comunidad. ${ }^{17}$ Parece significativo que lo que queda de las instituciones comunales en las sociedades complejas se relacione con mecanismos de control social de los miembros de la elite, un aspecto esencial de la organización de las comunidades igualitarias en todo tiempo y lugar.

\section{Asambleas y decisiones colectivas}

Todas las asociaciones humanas se organizan con el propósito de alcanzar algún bien, porque todos los hombres actúan con el objetivo de conseguir algo que, desde su punto de vista, es un bien. ${ }^{18}$

Uno de los procesos sociales que más claramente se refiere a formas de participación política de la gente común es la toma colectiva de decisiones. Prácticamente todos los pueblos que vivían como cazadores-recolectores cuando se encontraron por primera vez con los europeos, llegaban a decisiones colectivas mediante formas

\footnotetext{
15 Pauketat 2000.

16 FORSDYKe 2008.

17 Forsdyke 2008, 49-50.

18 Arist., Pol. 1252 a.
} 
informales de consenso entre los miembros del grupo (nota 3). Se trataba de grupos pequeños de familias que basaban su subsistencia en la producción cooperativa con la obligación de compartir los recursos en un contexto de ausencia relativa de dominio. Los pueblos igualitarios siempre han entendido muy bien que es humano buscar una concentración del poder y que si el poder se delega debe ser cuidadosamente controlado. Para ello era necesario que los grupos constantemente negociaran convenciones y normas que limitaran la competencia de los líderes y que promovieran la cooperación en el seno del grupo, en el contexto de las reuniones para la toma de decisiones.

Esta forma de vida ha sido la dominante para la mayor parte de los grupos sociales humanos durante decenas de miles de años ${ }^{19}$ y no solo entre grupos de cazadores-recolectores. También se han documentado sistemas similares de llegar a acuerdos colectivos en el seno de sociedades tribales de diversos tipos. En este caso, nos encontramos ante organizaciones sociales basadas en una estructura de grupos domésticos que, normalmente, carecen de formas de autoridad política centralizada aunque tengan líderes rituales o consejos compuestos por personas (normalmente hombres, aunque, a veces, también mujeres) mayores. En todos estos casos, la importancia de las asambleas está asociada con una fuerte vida comunitaria, donde se discuten temas relacionados con cualquier aspecto de las actividades comunales, incluyendo la resolución de conflictos y disputas.

Numerosos estudios etnológicos de grupos recolectores o tribales han proporcionado evidencia sobre los mecanismos de los procesos de toma de decisiones. En diversos grupos conocidos, las asambleas pueden asumir rasgos muy formalizados, organizándose de forma fija, regulando el lugar donde se sientan los participantes y marcando la agenda del debate. ${ }^{20}$ También existen normas respecto a los discursos pronunciados, porque la capacidad persuasiva de los oradores siempre ha sido importante en el proceso deliberativo. Para alcanzar una decisión en primer lugar alguien tiene que identificar y comunicar el problema que tiene que solucionarse. Es frecuente que algunos oradores alcancen en las reuniones una forma de liderazgo informal, con reconocimiento de su autoridad, basada en su conocimiento, experiencia y firmeza de personalidad, pero no en el uso de la coerción directa. En las discusiones de grupo esas personas pueden hablar más frecuentemente que los demás y normalmente sus opiniones son más respetadas. ${ }^{21}$ Pero no tienen autoridad formal: tan solo persuaden, pero no imponen su voluntad sobre los demás. Una de las formas de impedir que la capacidad de convencer a una audiencia en el espacio colectivo se convierta en fuente de poder más permanente es que, normalmente, un "líder" en determinada cuestión no siempre lo es. Ser experto en una cuestión no quiere decir que se sea experto en otros campos. De esa forma, en las sociedades con tendencia al igualitarismo, el liderazgo fluctúa entre diversos expertos en un escenario en que hay una falta general de competitividad. Se llega a las decisiones por consenso, lo que no quiere decir unanimidad de opinión. Al consenso se llega

19 KaPLAN et alii 2009.

20 Bцoch 1975, 6.

21 LEE 1982, 45. 
a través de una serie de juicios hechos por gente que tienen acceso a una misma información. ${ }^{22}$

En todo caso, es evidente que el poder persuasivo del discurso es uno de los aspectos esenciales del funcionamiento de la toma de decisiones y, por tanto, de la acción sociopolítica en las comunidades tradicionales. ${ }^{23}$ Para controlar el peligro de que un orador particularmente persuasivo se convierta en una figura dominante en el grupo, las sociedades igualitarias muestran un rechazo casi formalizado a reconocer la superioridad de un miembro del grupo. Por tanto, se han desarrollado estrategias para anular la arrogancia y forzar la humildad. Se minimizan las habilidades de las personas y se habla de los esfuerzos propios, como pequeños y despreciables. Esto funciona también en el caso de los oradores, es decir, de aquellas personas que durante una asamblea del grupo toman la palabra para plantear un problema y/o una posible solución. Su discurso potencialmente puede considerarse una presuposición de mayor conocimiento respecto al resto del grupo, basado en la experiencia, una mayor información, o simplemente como característica personal. Como la tendencia del grupo en las sociedades igualitarias es la de sospechar de quien se presenta como superior en cualquier dominio de acción (o discurso) social, el orador debe procurar paliar la imagen de superioridad. Los propios oradores son conscientes del sentimiento colectivo contra la arrogancia o superioridad individual. Para evitar que la audiencia suponga que el orador tiene deseos de llegar a ser superior a los demás, quienes hablan ante la comunidad en asamblea usan diversos mecanismos de ocultación. Una de esas estrategias consiste en iniciar el discurso con una retahíla de autoinculpaciones, usando una forma indirecta de expresión, de manera que la posición del orador parezca emerger de otra fuente. ${ }^{24}$ En la estrategia política cooperativa el poder excluyente es eliminado porque es inhibido.

Podríamos proponer una serie de rasgos de la asamblea como espacio político de los grupos humanos que mantienen o han mantenido una postura colectiva en los procesos de toma de decisiones:

a) Toma de decisiones cara a cara, en un contexto público.

b) Creación de espacios públicos que favorezcan la visibilidad entre los miembros del grupo.

c) Distribución regular e igualitaria de la información necesaria para el proceso deliberativo entre los miembros del grupo.

d) El debate se plantea para, en la medida de lo posible, llegar a un consenso, en base a los argumentos presentados. Si el consenso no es posible, la decisión se toma por mayoría.

e) Los oradores adquieren potencialmente una posición de gran autoridad colectiva. Esa posición implica normalmente el esfuerzo para convencer a todos los miembros de la reunión y, de ahí, la importancia atribuida a la capacidad de persuasión en la figura

22 Silberbauer 1982, 26.

23 MYers 1986.

24 MYers 1986, 437. 
ideal del líder quien, al mismo tiempo, tiene que presentarse como alguien capaz de respetar las opiniones de los presentes.

f) Los participantes aceptarán los resultados de la decisión que se tome como consecuencia de la deliberación realizada en el espacio público y ante los miembros del grupo. No existen normas previas que condicionen el proceso de toma de decisiones.

g) La transmisión del lenguaje del consenso en un discurso se permite presentar el comportamiento social del grupo como cooperativo y de consenso. De esa forma, los participantes en la asamblea articulan y reproducen en el proceso de la toma de decisiones un orden social que tiene como núcleo la premisa de la igualdad entre quienes participan (culturalmente) en el grupo. ${ }^{25}$

\section{Asambleas romanas}

Hasta hace relativamente poco, en el discurso historiográfico sobre la República Romana dominaba la descripción de una sociedad basada en enormes diferencias de riqueza y estatus. Un círculo limitado de familias aristocráticas, gracias a la acumulación de riqueza y de los roles políticos (magistraturas), militares (mandos) y religiosos (sacerdocios) más importantes, habrían ejercido un poder prácticamente indiscutible durante los años en que Roma adquiría, a través de la expansión militar y diplomática, el imperio. Esa elite era una oligarquía conservadora, guerrera, cuyas prioridades eran la adquisición de gloria y riqueza y el dominio del pueblo. Sin duda, debido a las divisiones internas basadas en las redes y alianzas familiares, existían diferencias de rango político en el seno de la aristocracia, pero, en principio, la cooperación entre los miembros de la clase dominante predominaba, sobre todo, frente al resto de la ciudadanía romana. La aristocracia dominaba los mecanismos del poder y de la iniciativa política. Puesto que controlaban las magistraturas, tenían el poder ejecutivo, ya que los magistrados no eran representantes de la voluntad popular. El resto de la ciudadanía, compuesta por los propietarios pequeños y medianos de tierras, los artesanos y pequeños comerciantes, constituía la base de un sistema sociopolítico jerarquizado. Puesto que se enfatizaba el papel de la aristocracia en la organización y control del sistema político, se eliminaba la posibilidad de una participación popular en la construcción de la cultura política romana.

Frente a esta visión simplificada de la división social en Roma, que prácticamente negaba la agencia de la mayor parte de los ciudadanos romanos en la toma de decisiones, se encontraba el hecho de que, durante la República, se mantuvieron en funcionamiento instituciones, desde magistraturas a asambleas, populares. Diversos autores, entre los que destaca la figura del historiador británico Fergus Millar, han planteado que una historia de la República Romana basada tan solo en la historia de su clase gobernante hace invisible la existencia y el papel de los demás ciudadanos romanos, el Populus Romanus, y, especialmente, la importante relación entre el discurso senatorial y la acción popular. ${ }^{26}$ Como consecuencia, en los últimos años, se

25 Murphy 1990.

26 Millar 1998, 197 y ss. 
ha desarrollado un debate sobre las interacciones entre las instituciones ligadas a la clase dominante romana, el Senado y las magistraturas, y las que se nutrían del resto del cuerpo ciudadano, especialmente, las asambleas. ${ }^{27}$

El tema principal del debate es la posibilidad de que los ciudadanos comunes mantuvieran cierto control sobre el sistema político republicano y, por tanto, sobre la formación de los conceptos políticos. Como ya hemos señalado previamente, es indudable que una de las imágenes más poderosas de la ideología política romana es un ideal de consenso entre los dos sectores sociales, la aristocracia y la plebe, en los procesos de toma de decisiones, para crear la representación de una comunidad única. Se ha considerado frecuentemente que la idea de ese consenso idealizado surgió durante el largo período de conflictos entre patricios y plebeyos durante la primera parte de la República. ${ }^{28}$ Sin embargo, se ha apuntado también que no parece demostrado que el patriciado haya existido como una casta cerrada desde el comienzo de la República, como demostraría el hecho de que aparezcan nombres no patricios entre los primeros cónsules. ${ }^{29}$ Parece que la narrativa sobre el conflicto formó parte del proceso de creación (y justificación) del poder de una elite dominante en construcción y que, frente a ese proceso, se dio una resistencia de la comunidad a los cambios crecientes en los procesos de toma de decisiones.

Las asambleas romanas, en teoría los cuerpos soberanos de la ciudad, estaban organizadas en unidades específicas de voto. En la asamblea centuriada, donde se elegían las principales magistraturas, los participantes estaban distribuidos en centurias según la riqueza. En la asamblea tribal (comitia tributa) y en la asamblea de la plebe (concilia plebis), la organización se basaba en las tribus, es decir, los distritos regionales del territorio romano. La votación por unidades tendía a favorecer a los ricos sobre los pobres y a los que vivían cerca de Roma respecto a los que vivían más lejos. Con todo, tan solo en las asambleas, donde todos los ciudadanos romanos tenían derecho a votar, se podían elegir los magistrados, aprobar leyes y tomar ciertas decisiones para la acción política y militar. También eran tradicionalmente tribunales de justicia. En la práctica, la elite senatorial durante gran parte del período republicano podía, casi siempre, mantener el control de las asambleas electorales y legislativas, en parte por la manipulación de los sistemas de votación, el secretismo de los procedimientos y por otras formas de poder informal.

Pero, en ciertos momentos, sobre todo a finales de la República, cuando un magistrado reformista hacía uso del derecho del tribuno a proponer leyes ante la asamblea de la plebe, el equilibrio dominante entre la elite senatorial y la plebe podía cambiar drásticamente. Los poderes formales de la asamblea de la plebe: elección de magistrados (los tribunos de la plebe) y votación de leyes, podían ser usados como armas de resistencia contra la autoridad de la elite senatorial.

Por otra parte, las asambleas romanas carecían de uno de los rasgos fundamentales de la asamblea en otro tipo de sociedades, incluyendo las poleis griegas: no tenía lugar debate o discusión y, como hemos visto, ése es el rasgo fundamental de

27 Morstein-Marx 2004; Connolly 2007.

28 FLOWER 2010, 523.

29 OAKLey 2004, 19. 
la asamblea como órgano de decisión comunal. Sin embargo, los procesos deliberativos públicos existieron en Roma, especialmente en el Foro, que funcionaba como espacio de interacción entre los miembros de la elite dirigente y los habitantes de la ciudad. ${ }^{30}$ En la plaza pública romana, se podían escuchar discursos de los senadores y magistrados sobre los más diversos temas relacionados con el funcionamiento del gobierno, en una especie de sistema político cara a cara. En parte, esto se debía a que, a pesar de la influencia y poder de los senadores, éstos estaban obligados a ganar los votos populares para el avance de su carrera política y militar. La legitimidad y la consolidación del poder de los grandes hombres de Roma se manifestaban a través del discurso público y estaban potencialmente sometidos a contestación.

Los principales debates tenían lugar en el contexto de las llamadas contiones, una forma de asamblea que se convocaba para escuchar discursos y en la que no se votaba, aunque frecuentemente los discursos trataban de temas que posteriormente serían votados en las asambleas regulares. ${ }^{31}$ La contio era convocada por un magistrado, frecuentemente un tribuno de la plebe, un cónsul, o un pretor. La característica que fundamentalmente diferenciaba a la contio de otras asambleas populares es que no tenía poder formal. Podía ser una reunión puramente informativa, sobre batallas o sobre emergencias que afectaban a la comunidad, ${ }^{32}$ o podía tener un papel esencial en la presentación de nuevas leyes. Antes de que se presentasen ante las asambleas formales para su votación, las propuestas eran discutidas en las contiones que actuaban como instrumento esencial de información para la ciudadanía. También ejercían una función de un cierto control sobre los magistrados. En su primera contio después de asumir un cargo, los magistrados superiores no solo agradecían al Pueblo su elección, sino que indicaban cómo administrarían su magistratura; los pretores sobre todo describían cómo dispensarían justicia. Al final de su mandato, los magistrados, incluyendo los cónsules, juraban en otra contio que habían llevado a cabo su función de acuerdo a las leyes.

En principio, el acceso a este tipo de asambleas de debate estaba abierto a todos los ciudadanos que quisieran participar. Se reunían en el Foro, un escenario cargado de memoria histórica, a través de los monumentos y esculturas que se habían ido acumulando durante generaciones y funcionaban como recuerdo potente de los líderes pasados y de la historia de la propia Roma. ${ }^{33}$ El magistrado que convocaba la reunión la presidía, y actuaba como orador, junto a otros oradores que eran invitados a participar y que podían ser otros magistrados y, más raramente, ciudadanos privados. Es probable que la mayor parte del público asistente en cada ocasión fuese esencialmente urbano, excepto en ocasiones especiales en que el tema pudiese interesar de forma especial a la población rural. ${ }^{34}$ La contio, lugar de encuentro entre los líderes políticos y el pueblo, representaba el punto de encuentro de las dos entidades que conjuntamente constituían el consenso "idealizado" de la República es decir, el

\footnotetext{
30 Millar 1998, 224.

31 Pina Polo 1995.

32 Liv. 39.15.6.

33 Morstein-Marx 2004, 79.

34 Mouritsen 2001, 41.
} 
orden senatorial y el pueblo romano. Resultaba un escenario de primer orden para los oradores romanos, aquellos individuos pertenecientes a la elite aristocrática que deseaban hacer carrera pública. Aunque no se votaba, los oradores se veían obligados a apelar continuamente a la plebe, para responder a sus reacciones. Además, en los discursos de los oradores se hacían constantes alusiones al pasado y a los hechos importantes de las grandes familias. El propio discurso servía para el propósito de la autorrepresentación de los oradores, que pertenecían a la elite dominante. Puede decirse que la oratoria directamente reflejaba y mediaba la negociación histórica del poder en la República Romana, entre los miembros de la elite senatorial y el resto de la ciudadanía. Salustio describe la reacción popular ante el veto de un tribuno en una asamblea de la plebe:

la multitud que estaba presente en la reunión se agitó violentamente e intentó intimidar al tribuno con sus gritos, su expresión, con empujones, y cualquier otro tipo de acción a la que eran incitados por la ira. ${ }^{35}$

Esa forma indirecta de participación de los ciudadanos, como observadores e interlocutores vocales y gestuales, era importante para los miembros de la elite romana, que tomaban buena cuenta de las respuestas de la audiencia a los discursos de los oradores en las asambleas y, especialmente, en las contiones. El discurso en la contio muestra indicios de una noción tradicional del valor de la deliberación pública abierta ante la ciudadanía. Se puede presumir que probablemente este escenario y estas formas de interacción mantenían, en forma residual, raíces muy antiguas de un mundo comunal en el que todos los miembros del grupo participaban de forma activa en los procesos de toma de decisión. La oratoria ante las masas en la contio renovaba constantemente las conexiones comunales entre los oradores de la elite y los oyentes votantes, uniendo al ciudadano común al tejido de la res publica aunque fuera al servicio de las ideas y propuestas formuladas por la elite.

\section{La rendición de cuentas y la asamblea ateniense}

En el siglo IV a.C. la asamblea de los ciudadanos se reunía unas 40 veces al año, en una pequeña colina rocosa, Pnyx, situada a unos 500 metros al suroeste del Agora (Fig. 1). Los ciudadanos ocupaban una gran plataforma artificial, construida a finales del siglo V a.C., y aquéllos que deseaban dirigirse a la asamblea lo hacían desde una plataforma excavada en la roca (bema), cercana a la cima de la colina. El espacio de la asamblea tenía una forma semicircular, similar a la de los teatros. Allí se reunían entre 6000 y 8000 ciudadanos que representaban entre una y dos quintas partes de la población ciudadana total. La ubicación de los asistentes era igualitaria: ricos y pobres, elite y comunes se sentaban juntos. Aunque la audiencia concreta de una

35 Sall., Yug. 34.1 (se ha empleado la edición de Gredos, Madrid, 1990, con traducción de J. García Álvarez). 
asamblea era siempre una fracción del cuerpo ciudadano, a todos los efectos, se consideraba que representaba a toda la ciudadanía ateniense.

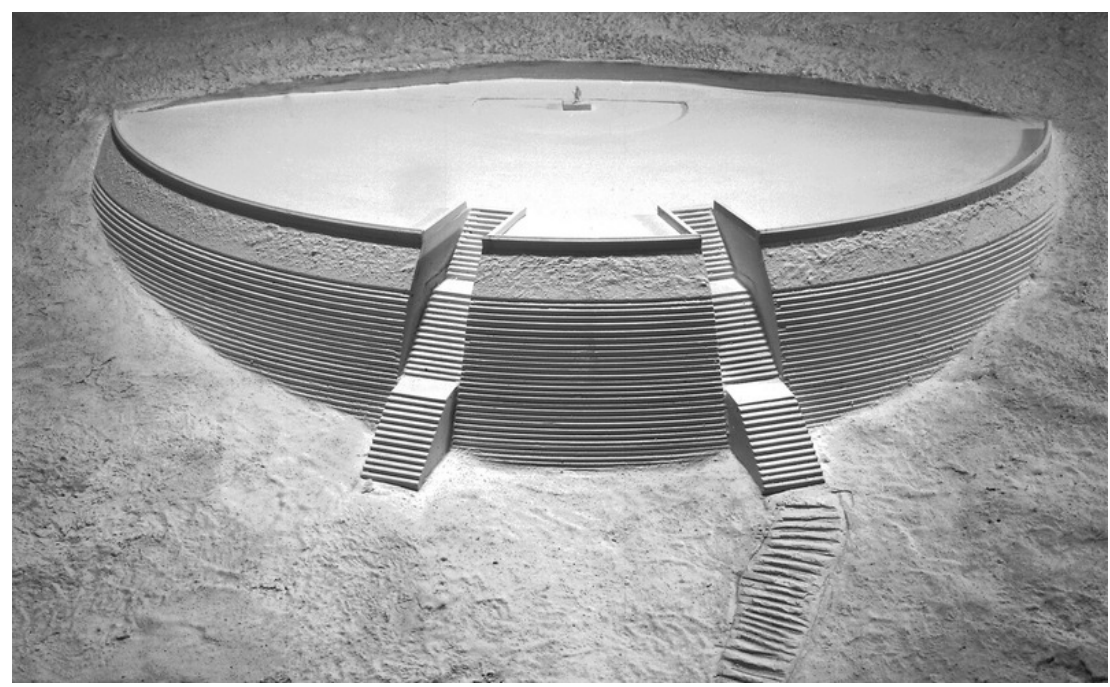

Fig. 1. Modelo de la organización espacial del Pnyx, c.400-345 a.C.

Museo del Agora, Atenas. Fotografía de la web de las excavaciones del Agora (http://www. agathe.gr/).

También en el caso de la democracia ateniense, la comunicación entre la elite y el demos tenía lugar en la asamblea y en los demás foros donde se deliberaba y tomaban decisiones. Se nos han conservado un centenar y medio de discursos pronunciados ante la asamblea y los tribunales por diversos oradores de los siglos V y IV a.C. El buen orador era una figura pública reconocida en Atenas, que podía alcanzar notable influencia a través de sus participaciones en la asamblea y, con frecuencia, en los juicios contra sus rivales políticos y sociales. Su capacidad para la creación (y la representación) de discursos persuasivos constituían la base fundamental de su poder de liderazgo a través de la comunicación directa con el demos ateniense. Los 'oradores regulares' no pertenecían a un grupo constituido y no tenían una posición institucional determinada. Sus frecuentes intervenciones en la asamblea y su influencia se debían a la aceptación -que nunca podía considerarse segura-del demos. Además, aun cuando hablasen con mayor frecuencia o tuviesen mayor capacidad persuasiva, en cualquier asamblea los demás ciudadanos podían participar, discutir los diversos temas, proponer leyes y decretos. El ciudadano que decidía participar podía proponer un voto negativo sobre una cuestión planteada, una revisión de la propuesta o una propuesta completamente nueva. Y podía hacerlo durante tanto tiempo como sus conciudadanos se lo permitiesen. Cuando los participantes en la asamblea se cansaban de escuchar a un orador, le gritaban que se callase. Después de que todos los que querían participar lo habían hecho, el presidente dirigía el voto, usualmente a mano alzada. Una mayoría simple era suficiente y se seguía con el siguiente tema. 
El demos en la asamblea votaba a favor o en contra de la propuesta a partir de los argumentos del orador o de sus oponentes y a partir del valor que les concedía como ciudadanos. Si un orador lograba convencer a su audiencia de su estatus como ciudadano ejemplar, al tiempo que lograba socavar la imagen de sus adversarios, sabía que tendría más posibilidades de que su propuesta o su caso obtuvieran una mayoría de votos de los participantes en la asamblea o de los jurados del tribunal. En el discurso contra Timarco, Esquines ${ }^{36}$ atribuye el origen del proceso a la convicción de que ningún hombre "puede ser un villano en su vida privada y un hombre excelente en los asuntos públicos". Ese énfasis en la necesidad de la excelencia del comportamiento privado de quienes desean tener una vida política activa, recorre el funcionamiento de las instituciones políticas atenienses y forzaba a que la vida de los políticos estuviese abierta al escrutinio de la moralidad popular.

En su análisis del discurso de Demóstenes, Contra Midias, Ober ha ofrecido un análisis de la relación entre oratoria y poder, así como de los límites del comportamiento considerado apropiado para los individuos más poderosos de la sociedad ateniense. ${ }^{37}$ En la primavera de 348 a.C. Demóstenes tenía a su cargo la preparación del coro de la tribu Pandianis para las celebraciones del Festival de Dionisio. Sus preparativos se vieron dificultados de diversas formas por Midias, un político conocido y rico que mantenía un conflicto con Demóstenes. En un determinado momento, Midias abofeteó a Demóstenes, quien presentó un tiempo después cargos contra él. El discurso Contra Midias representa la propuesta de Demóstenes, como acusador. Es un excelente ejemplo de un enfrentamiento legal entre dos miembros de la elite ateniense que, además, eran parte de los 'oradores regulares', es decir, de aquellos que frecuentemente intervenían en la asamblea. Como parte de la estrategia de la acusación, Demóstenes trata de establecer una serie de diferencias entre él y Midias. Mientras este último aparece caracterizado como un hombre rico y arrogante (98), que desprecia al demos, como si estuviera compuesto por "mendigos, la escoria de la tierra, como si fueran nada" (185). Además usa su riqueza para destruir a los ciudadanos ordinarios que le impiden obtener sus deseos (109). Demóstenes sugiere que, de hecho, el comportamiento de Midias respecto al demos, corresponde a la tendencia antidemocrática propia de la elite de los ricos que quieren controlar la ciudad y no tienen respeto por la gente común. En contraste, Demóstenes se representa como un ciudadano modelo que ha sido hoplita y que se escandalizó por la cobardía mostrada por Midias en el campo de batalla (133). En su actividad política, Demóstenes enfatiza su preocupación por el bien público y el hecho de que su único apoyo es el propio demos, mientras Midias depende del apoyo de su familia. En cuanto a la riqueza, mientras Midias la usa para la exhibición pública que le sirve para humillar a los ciudadanos comunes (158), él únicamente la utiliza para el bien público.

¿Cuál es, por tanto, la única solución para el demos ante la agresión de los hombres como Midias que intentan establecer el dominio sobre los demás ciudadanos? Tienen que actuar colectivamente, en defensa de las leyes y las normas democráticas (14042) y Demóstenes se presenta como el hombre que puede enfrentarse al peligro que

36 Esquines, 1.30.

37 OBER 1994. 
representa Midias, llevándolo ante la justicia. Y los jurados que le escuchan tienen que usar del poder colectivo que representan para impedir que un miembro de la elite destruya el sistema democrático. Es la acción colectiva la que ha de defender el poder y la dignidad de la comunidad, valor democrático por excelencia. En este discurso y en otros Demóstenes reflexiona sobre el peligro que representa la habilidad oratoria en la toma de decisiones y considera que el buen orador tiene que, simplemente, dar voz a los deseos de la mayoría.

Este discurso muestra el hecho de que los oradores políticos atenienses pertenecían, normalmente, a la elite. Muchos de ellos aparecen en la lista de las personas que pagaban liturgias, servicio público obligatorio para los más ricos. Su papel en el funcionamiento de la toma de decisiones ateniense era, sin duda, importante, pero la ciudadanía había creado mecanismos diversos para evitar que los miembros de la elite usasen las instituciones y, especialmente, las asambleas, como una forma de defender sus intereses de clase frente a los demás miembros de la ciudadanía.

Los ciudadanos elegidos para ocupar un cargo público pasaban por un escrutinio público riguroso (dokimasia) antes de acceder a su función en el que se contemplaba, sobre todo, que cumpliesen los requisitos necesarios, desde el nacimiento en una familia ciudadana a su comportamiento cívico, es decir, si habían cumplido con los deberes militares y las obligaciones religiosas. En el caso de ser culpable de negligencia en esos deberes ciudadanos o si se demostraba que había maltratado a sus padres o que había ejercido la prostitución, cualquier ciudadano perdía el derecho a hablar ante la asamblea. ${ }^{38}$ Después de dejar el cargo, existía una auditoria pública (euthunai), sobre las finanzas de los ex magistrados. Además, una parte de ese proceso se realizaba en el Agora, lo que permitía que cualquier ciudadano pudiese plantear sus quejas. Hasta que el proceso no había terminado, los derechos del ex magistrado estaban limitados: no podía viajar, transferir propiedad o hacer ofrendas a los dioses. ${ }^{39} \mathrm{Si}$ era encontrado culpable de mala gestión o de corrupción las consecuencias podían ser graves, normalmente en forma de severas multas económicas que si no eran pagadas podían acarrear la pérdida de los derechos cívicos ${ }^{40}$ En todo caso, cualquier ciudadano que tomara la palabra ante la asamblea, fuese un 'orador frecuente' o un participante esporádico, estaba sometido al juicio popular, fuese a partir de la reacción ruidosa de la audiencia, del chismorreo que acompañaba a los personajes públicos de Atenas o al ridículo de los autores de las comedias. Una de las premisas básicas del sistema democrático ateniense era que todos los ciudadanos tenían el derecho de hacer propuestas y de hablar ante la asamblea, pero que eran responsables de esas actividades y debían rendir cuentas. Ese aspecto, el de la rendición de cuentas, implicaba el indispensable control sobre quienes ejercían alguna función de gestión en la administración del Estado.

Otros mecanismos de rendición de cuentas, aparte de los ya mencionados, funcionaban en Atenas. El más conocido, el ostracismo, se aplicaba en teoría a todos los ciudadanos, aunque normalmente los elegidos pertenecían a la elite social de la ciudad.

38 OBER 1989, 109-110.

39 Roberts 1982, 18.

40 SinClair 1991, 154. 
La ley del ostracismo permitía a la asamblea exiliar a un ciudadano, normalmente perteneciente a la elite social, durante un periodo de diez años. Era la forma más extrema en la que el demos podía reprimir el poder de un individuo que se consideraba una amenaza para el sistema democrático. De hecho, la ideología democrática tendía a considerar al rico como potencialmente hostil al régimen político democrático. Los ciudadanos ordinarios sospechaban de las pretensiones individuales, no solo a la riqueza y al estatus, sino a un conocimiento político especial o superior. Los atenienses compartían la idea que Aristóteles propone en la cita que abre este trabajo, ${ }^{41}$ en el sentido de valorar la sabiduría de la masa como el mejor juez posible en asuntos de importancia. Además no consideraban necesaria una educación o habilidad especiales para ejercer como ciudadanos en la toma de decisiones colectivas. El hecho de crecer en una polis democrática era suficiente entrenamiento no solo para ser ciudadano, sino para participar activamente en todo tipo de práctica política. ${ }^{42}$

El número de oradores que participaba en una asamblea era, probablemente, reducido y la participación de la masa de ciudadanos atenienses, como en el caso de la plebe romana en la contio, debía ser esencialmente vocal e informal, mediante gritos, murmullos y aclamaciones. Con todo, los puntos de vista de los asistentes a la asamblea ateniense, en contraste con lo que sucedía en el caso romano, eran un elemento clave en los procesos de toma de decisiones. Mediante las formas de comunicación oral mencionadas y a través del juicio colectivo que se expresaba mediante la votación de las propuestas presentadas, el demos controlaba las opiniones colectivas. De esta forma el debate sobre el que se establecían las negociaciones sociales en la asamblea y en los tribunales, se creaba y reformaba constantemente a partir de las creencias y opiniones colectivas. La identidad cívica se construía en parte a partir de las estrategias usadas para contener la tendencia al dominio de los miembros de la elite. ${ }^{43}$ La defensa con éxito de la democracia contra las elites se basaba en el dominio por la ciudadanía del aparato conceptual esencial para la toma de decisiones. Los procedimientos del debate en la asamblea y en los tribunales colocaban a los oradores en situación de competición con otros oradores. La elite ateniense vivía y operaba bajo condiciones de inestabilidad institucionalizada. En el caso ateniense, una sociedad jerarquizada, la función de los oradores se desarrolló como un instrumento para negociar las tensiones provocadas por la riqueza y los privilegios en un sistema político que defendía la igualdad entre los ciudadanos. En última instancia, el poder político de los ciudadanos comunes se mantuvo a través del control del discurso público.

La asamblea ateniense y, en cierta medida, la contio romana, compartían algunos de los rasgos que hemos señalado en relación a la toma de decisiones en las sociedades con una ideología predominantemente igualitaria. Aunque la población de Atenas y la de Roma eran relativamente numerosas, el lugar de encuentro comunal (Pnyx y el Foro) se organizó espacialmente para favorecer el cara a cara de los presentes. Por otra parte, se ha enfatizado recientemente la importancia de la distribución entre los ciudadanos atenienses de la información previa necesaria para la toma de decisiones

41 Se ha empleado la edición de Espasa Calpe, Madrid, 1997, con traducción de P. de Azcárate Corral.

42 OBER 1996, 26.

43 Cohen 1995, 191. 
colectiva. ${ }^{44}$ También en Roma, la contio tenía una función esencialmente informativa en relación a la plebe. Tanto en Atenas, como en Roma, como hemos visto, la capacidad de persuasión podía dar a un orador una posición de autoridad comunal que en el caso ateniense se veía limitada por la necesidad constante de respetar los valores de la ideología democrática, especialmente el que se refería al peligro del individuo que alcanzaba demasiada influencia. Esa creencia estaba estrechamente ligada a la necesidad de defender la igualdad de todos los que participaban del grupo, los ciudadanos atenienses.

\section{Conclusiones}

La narrativa sobre la emergencia de las sociedades complejas ha enfatizado normalmente el surgimiento de las elites, las dinastías reales y sus culturas materiales. Ese discurso emergió en parte por la importancia que las primeras expediciones arqueológicas daban a las grandes estructuras, templos o palacios, o a las grandes tumbas y sus ricos ajuares funerarios, que permitían llenar las primeras colecciones de los museos europeos y americanos. Pero también se debía al contexto social del que procedían los investigadores, que no les permitía considerar importante la acción de la gente común en el surgimiento de las antiguas civilizaciones. El funcionamiento de las sociedades antiguas se consideraba como una etapa precursora del hecho contemporáneo del dominio prácticamente global de elites sociales. ${ }^{45}$

De igual forma, el discurso del surgimiento y decadencia de dinastías leídos en términos de etapas de esplendor y crecimiento frente a etapas de oscuridad y decadencia ha seguido vigente en la historiográfica del mundo antiguo. Ha servido en cierta medida como discurso legitimador de la inevitabilidad de la emergencia de elites ligadas, aparentemente por su propia presencia, a los cambios tecnológicos y los avances artísticos, es decir, a la evolución de un progreso que nos ha llevado al mundo actual. Esto siempre ligado a la sumisión y, de hecho, invisibilidad, del resto de la sociedad. Este tipo de narrativa se sostiene, y a su vez sostiene, en la idea de que es "buena" la existencia de especialistas en el manejo de los asuntos públicos, que hacen funcionar de manera más efectiva y ordenada las sociedades. En última instancia, estos "ordenadores" aparecen en el relato histórico como los responsables del "progreso" como objetivo final e indiscutible del devenir histórico. Puesto que se considera un proceso inevitable se da menor énfasis al hecho de que los individuos o grupos que se transformaron en elites lo hicieron contra y explotando al resto de los miembros de la sociedad. Se olvida que los que consiguen el poder son aquellos que manipulan, presionan, fuerzan una situación de poder, son los "reyes devoradores de dones", es decir, los que buscan su propio engrandecimiento.

Ese mismo tipo de narrativa se ha usado para describir otras sociedades históricas. La Europa de finales de la Edad Media y comienzos de la Edad Moderna se ha descrito usualmente como aristocrática, monárquica, feudal y, por tanto jerárquica en su es-

44 OBER 2010.

45 Pauketat 2000,113. 
tructura política. Sin embargo, estudios recientes han enfatizado la importancia de las ciudades y asentamientos rurales que lucharon durante siglos para mantener sus derechos a articularse políticamente como comunidades. Esa activa vida colectiva estaba presente en casi toda Europa. Los campesinos en algunas regiones europeas lograron mantener la autonomía de sus comunidades. Resolvían sus desacuerdos a través de la negociación, por acuerdos mutuos que hacían referencia al "bien común". ${ }^{46}$

En todo caso, se ha dado poca importancia y poco esfuerzo investigador a aquellas formas de organización de poder local basado en formas colectivas de toma de decisión que continuaban existiendo junto a los poderes centralizados y que muy probablemente, los precedieron. Así se explican las asambleas antiguas, medievales o modernas, en función de cómo eran manipuladas, restringidas, y en últimas instancias inoperantes, y no en relación a las cotas de poder colectivo que representaban.

En muchas sociedades humanas - probablemente la mayoría de ellas-se han llevado a cabo políticas activas contra los individuos ambiciosos que intentaban obtener el poder. Frente a la opinión muy difundida -incluso desde la historia académica- ${ }^{47}$ de que es inevitable la aparición de machos alfa porque está en la naturaleza humana, lo cierto es que un sentimiento mucho más generalizado es el de no querer ser sometido, explotado, engañado y manipulado en beneficio de un individuo o unos pocos.

En este trabajo hemos planteado la necesidad de rastrear en las sociedades arcaicas aquellas instituciones o formas de poder local o colectivo que se conservaron en las sociedades complejas y que probablemente se remontaban a etapas anteriores a la aparición de formas de poder centralizado. Y sobre todo, hemos intentado establecer que siguieron existiendo formas colectivas de toma de decisiones más o menos residuales que mantenían la iniciativa y la agencia de los grupos colectivos.

Durante milenios, la mayoría de las comunidades humanas construyeron un contrato social basado en la identificación, aislamiento y, en algunos casos, la eliminación de aquellos individuos cuyo comportamiento social inapropiado implicaba un peligro -real o potencial- de convertirse en lo suficientemente poderosos como para poder usar el trabajo de los demás en su deseo de satisfacer sus propios deseos y acumular bienes y riqueza. La gradual eliminación de los mecanismos de exclusión social de los acumuladores, fue el paso necesario para la creación de jerarquías sociales basadas en la desigualdad, pero no significó la desaparición absoluta de la comunidad y de su importancia en los procesos de toma de decisiones, que seguía teniendo como escenario prioritario la asamblea, el lugar en el que se seguía manteniendo un reconocimiento del poder del grupo para decidir sobre la comunidad. Y esa evidencia puede formar parte también del proyecto de un futuro en el que los que son más decidan cómo y de qué forma quieren organizar y, sobre todo, controlar el funcionamiento de sus sociedades. Las comunidades antiguas nos demuestran que si se dan las circunstancias apropiadas, podemos compartir lo que tenemos y reprimir a quienes usan a los demás exclusivamente en su propio beneficio.

46 Neveux - Osterberg 1997, 177-179.

47 A partir de la influencia en la historiografia de la "ley de hierro de la oligarquía", desarrollada por el sociólogo alemán Robert Michels a principio del siglo XX. 


\section{Bibliografía}

Bloch, M. (1975): "Introduction”, [en] M. Bloch (ed.), Political Oratory in Traditional Society, London-New York, 1-28.

BRADY, T. A. (1997): "Cities and state-building in the south German-Swiss zone of the "urban belt", [en] P. Blickle (ed), Resistance, Representation, and Community, Oxford, 236-250.

Cohen, D. J. (1995): Law, violence, and community in classical Athens, Cambridge.

Connolly, J. (2007): The State of Speech: Rhetoric and Political Thought in Ancient Rome, Princeton.

Flower, H. I. (2010): “The Imperial Republic”, [en] A. Barchiesi - W. Schidel (eds.), The Oxford Handbook of Roman Studies, Oxford, 519-532.

Forsdyke, S. (2008): "Street Theatre and Popular Justice in Ancient Greece: Shaming, Stoning and Starving Offenders inside and outside the Courts", Past and Present 201, 3-50.

Griffith, M. (1998): "The King and Eye: the Rule of the Father in Greek Tragedy", Proceedings of the Cambridge Philological Society 44, 20-84.

Joyce, A. - Bustamante, L. A. - Levine, M. (2001): "Commoner Power: A Case Study from the Classic Period "Collapse" on the Oaxaca Coast", Journal of Archaeological Method and Theory 8/4, 343-385.

LeE, R. (1982): "Politics, sexual and non-sexual, in egalitarian society", [en] E. Leacock - R. Lee (eds.), Politics and history in band societies, Cambridge, 37-59.

LowIE, R. (1973): "Political Organization among American Indians", [en] D. Black - M. Mileski (eds.), Social Organization of Law, New York, 278-303.

Millar, F. (1998): The Crowd in Rome in the Late Republic, Ann Arbor, Michigan.

Morris, I. (1996): "The Strong Principle of Equality and the Archaic Origins of Greek Democracy", [en] J. Ober-C. Hedrick (eds.), Demokratia: A Conversation on Democracies, Ancient and Modern, Princeton, 19-48.

Morstein-Marx, R. (2004): Mass oratory and political power in the Late Roman Republic, Cambridge.

Murphy, W. P. (1990): “Creating the Appearance of Consensus in Mende Political Discourse", American Anthropologist 92/1, 24-41.

Myers, F. R. (1986): "Reflections on a Meeting: Structure, Language, and the Polity in a Small-Scale Society", American Ethnologist 13/3, 430-447.

Neveux, H. - Osterberg, E. (1997): "Norms and values”, [en] P. Blickle (ed.), Resistance, Representation, and Community, Oxford, 155-215.

OAKley, S. P. (2004): “The Early Republic", [en] H. I. Flower (ed.), The Cambridge Companion to Roman Republic, Cambridge, 15-30.

OBer, J.

(1989): Mass and elite in democratic Athens: rhetoric, ideology, and the power of the people, Princeton.

(1994): "Power and oratory in democratic Athens: Demosthenes 21, against Meidias", [en] I. Worthington (ed.), Persuasion. Greek Rhetoric in Action, London-New York, 85-108. (1996): The Athenian Revolution. Essays on Ancient Greek Democracy and Political Theory, Princeton. 
(2010): Democracy and Knowledge: Innovation and Learning in Classical Athens, Princeton.

Pauketat, T. R. (2000): “The tragedy of the commoners”, [en] M. Dobres - J. E. Robb (eds.), Agency in Archaeology, London, 113-129.

Picazo, M. (2013): “Reprimir a los 'reyes devoradores de dones': mecanismos de control social en la Grecia antigua”, [en] R. M Cid López - E. García Fernández (eds.), Debita verba. Estudios en Homenaje al profesor Julio Mangas Manjarrés, Oviedo, vol. I, 513-524.

Pina Polo, F. (1995): "Procedures and Functions of Civil and Military contiones in Rome", Klio 77, 203-16.

RaAflaub, K. A.(1997): "Homeric Society", [en] I. Morris - B. Powell (eds.), A New Companion to Homer, Leiden, 624-648.

Roberts, J. T. (1982): Accountability in Athenian government, Madison, Wis.

Robinson, E. W. (1997): The First Democracies: Early Popular Government outside Athens, Stuttgart.

SchwartzberG, M. (2010): "Shouts, Murmurs and Votes: Acclamation and Aggregation in Ancient Greece", The Journal of Political Philosophy 18/4, 448-468.

Silberbauer, G. (1982): "Political process in G/wi bands", [en] E. Leacock - R. Lee (eds.), Politics and history in band societies, Cambridge, 23-35.

SinClaiR, R. K. (1991): Democracy and participation in Assembly, Cambridge.

Yoffee, N.

(2000): "Law courts and the mediation of social conflict in ancient Mesopotamia", [en] J. Richards - M. van Buren (eds.), Order, Legitimacy, and Wealth in Ancient States, Cambridge, 46-63.

(2005): Myths of the Earliest Cities, States, and Civilizations, Cambridge. 